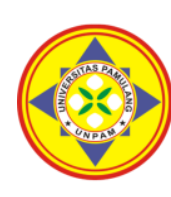

\title{
PENGARUH LINGKUNGAN KERJA DAN DISIPLIN KERJA TERHADAP KINERJA PEGAWAI PADA BALAI BESAR PENGEMBANGAN PENJAMIN MUTU PENDIDIKAN VOKASI (BBPPMPV) BISNIS DAN PARIWISATA
}

\author{
${ }^{1}$ Akmaludin, ${ }^{2 *}$ Bunga Astra Gracia \\ Universitas Pamulang, Tangerang Selatan, Banten, Indonesia \\ *dosen01016@unpam.ac.id
}

\begin{abstract}
Abstrak
Penelitian ini bertujuan untuk mengetahui pengaruh lingkungan kerja dan disiplin kerja terhadap kinerja pegawai pada Balai Besar Pengembangan Penjamin Mutu Pendidikan Vokasi (BBPPMPV) Bisnis dan Pariwisata. Metode yang digunakan adalah metode asosiatif dengan menggunakan analisis statistik uji validitas, uji reliabilitas, uji asumsi klasik, analisis regresi, analisis koefisien korelasi, analisis koefisien determinasi dan uji hipotesis. Hasil penelitian persamaan regresi linear sebesar $Y=9,229+0,397 X 1+0,730 X 2$. Lingkungan kerja dan Disiplin kerja secara simultan berpengaruh signifikasi terhadap Kinerja Pegawai pada Balai Besar Pengembangan Penjamin Mutu Pendidikan Vokasi (BBPPMPV) Bisnis dan Pariwisata, hal ini dapat diperoleh nilai $\mathrm{F}_{\text {hitung }}>\mathrm{F}_{\text {tabel }}$ yaitu didapat bahwa 70,959 > 2,39 dengan tingkat signifikasi 0,000<0,10.
\end{abstract}

Kata Kunci: Lingkungan Kerja, Disiplin Kerja, Kinerja Pegawai

\section{Abstract}

This research aims to find out the influence of the work environment and work discipline on employee performance at the Center for The Development of Vocational Education Quality Assurance (BBPPMPV) Business and Tourism. The method used is an associative method using statistical analysis of validity tests, reliability tests, classical assumption tests, regression analysis, correlation coefficient analysis, determination coefficient analysis and hypothesis tests. The results of the linear regression equation equation of $Y=9,229$ $+0.397 X 1+0.730 X 2$. The work environment and work discipline simultaneously affect the performance of employees at the Center for The Development of Vocational Education Quality Assurance (BBPPMPV) Business and Tourism, this can be obtained Fhitung value $>$ Ftabel which is obtained that 70,959>2.39 with a signification rate of $0.000<0.10$.

Keywords: Work Environment, Work Discipline, Employee Performance

\section{PENDAHULUAN}

Pada sebuah organisasi perusahaan sumber daya manusia (SDM) pada dasarnya merupakan salah satu modal dan memegang peran penting dalam mencapai tujuan perusahaan. Begitu juga di era globalisasi saat ini, sumber daya manusia merupakan aspek yang krusial untuk menunjang produktivitas sebuah perusahaan agar mampu bertahan diketatnya persaingan.

Peran Sumber Daya Manusia (SDM) dalam suatu organisasi memiliki kedudukan yang penting pada pelaksanaan proses kerja organisasi dan pencapaian tujuan organisasi. Dalam pelaksanaannya, manusia dalam organisasi ini menjadi elemen utama dibandingkan dengan sumber daya yang lain.

Tanpa adanya sumber daya manusia, sumber daya yang lain tentunya tidak akan bisa dimanfaatkan. Meskipun banyak faktor yang mempengaruhi organisasi seperti mesin-mesin modern, modal yang kuat, teknologi dan sistem yang canggih, tetapi tanpa adanya manusia yang menangani dan mengelolanya tidak akan berarti bagi perkembangan organisasi. Ini jelas menunjukan bahwa Sumber Daya Manusia menentukan survive nya suatu organisasi termasuk organisasi pemerintahan.

Kedudukan dan peran Pegawai Negeri Sipil sebagai unsur Aparatur Sipil Negara (ASN) yang bertugas sebagai abdi 
masyarakat harus menyelenggarakan pelayanan secara adil kepada masyarakat dengan dilandasi kesetiaan dan ketaatan kepada Pancasila dan Undang-Undang Dasar 1945. Untuk dapat melaksanakan tugas dengan baik, maka pembinaan pegawai diarahkan untuk meningkatkan kualitas sumber daya manusia agar memiliki sikap dan perilaku yang berintikan pengabdian, kejujuran, tanggung jawab, disiplin serta wibawa sehingga dapat memberikan pelayanan sesuai tuntutan perkembangan masyarakat.

Balai Besar Pengembangan Penjamin Mutu Pendidikan Vokasi (BBPPMPV) Bisnis dan Pariwisata merupakan salah satu unit pelaksana teknis dilingkungan Kementerian Pendidikan dan Kebudayaan dibidang Balai Besar Pengembangan Penjamin Mutu Pendidikan Vokasi (BBPPMPV) Bisnis dan Pariwisata berada dibawah dan bertanggung jawab kepada Direktorat Jenderal Guru dan Tenaga Kependidikan.

\section{BBPPMPV Bisnis dan Pariwisata} mempunyai tugas melaksanakan pengembangan dan pemberdayaan pendidik dan tenaga kependidikan sesuai dengan bidangnya. Pendidikan dan pelatihan yang dilakukan oleh BBPPMPV Bisnis dan Pariwisata akan dapat berjalan dengan baik karena salah satunya dipengaruhi oleh kinerja Pegawai dalam melakukan kegiatan persiapan, pelaksanaan dan pengevaluasian pendidikan dan pelatihan.

Balai Besar Pengembangan Penjamin Mutu Pendidikan Vokasi (BBPPMPV) Bisnis dan Pariwisata merupakan salah satu unit pelaksana teknis di lingkungan Kementerian Pendidikan dan Kebudayaan berada dibawah dan bertanggung jawab kepada Direktorat Jenderal Guru dan Tenaga Kependidikan. Berdasarkan Permendikbud No. 16 Tahun 2015 BBPPMPV Bisnis dan Pariwisata mempunyai peran yang sangat strategis dan sentral dalam meningkatkan kualitas dan profesionalitas pendidik dan tenaga kependidikan di Indonesia.
BBPPMPV Bisnis dan Pariwisata memberikan layanan pendidikan dan pelatihan berstandar internasional, penelitian dan pengembangan, serta layanan konsultasi kepada pendidik dan tenaga kependidikan serta masyarakat dibidang Bisnis dan Pariwisata. Untuk mewujudkan kebijakan tersebut maka seluruh pimpinan dan pegawai bertekad untuk menerapkan sistem manajemen mutu, memberikan pelayanan prima serta selalu meningkatkan mutu layanan dengan menerapkan dan menjunjung nilai professional, integritas, religious, mandiri, gotong royong, dan nasionalis.

Sumber daya manusia merupakan bagian yang cukup penting dalam pencapaian tujuan organisasi, baik itu perusahaan besar atau kecil. Suatu perusahan memiliki peralatan yang modern dengan teknologi tinggi, manusia merupakan motor penggerak, tanpa manusia perusahaan tidak akan berfungsi. Tujuan memahami dan mempelajari manajemen sumberdaya manusia sebagai suatu pengetahuan yang di perlukan untuk memiliki kemampuan analisa dalam menghadapi masalah-masalah manajemen sumberdaya manusia khususnya di bidang organisasi.

Menciptakan sumber daya manusia yang sangat berkualitas dan berdaya guna, sebuah perusahaan harus menciptakan kondisi lingkungan kerja yang baik, secara fisik maupun non fisik. Lingkungan kerja mempunyai kontribusi yang cukup besar dalam peningkatan kinerja karyawan.

$$
\text { Lingkungan kerja mengarah }
$$
kebeberapa aspek diantaranya manajemen, struktur organisasi dan deskripsi kerja, kebebasan, lingkungan fisik yang memuaskan, seperti tersedianya tempat ibadah, ruang yang cukup nyaman dalam bekerja, ventilasi, dan keamanan. Di BBPPMPV Bisnis dan Pariwisata para karyawan sering mengeluh tentang kondisi lingkungan kerja yang kurang baik, seperti penerangan di tempat kerja mereka, suara bising yang dihasilkan oleh alat-alat produksi karena sedang adanya renovasi banguan yang bertahap yang 
mengakibatkan karyawan kurang nyaman dalam bekerja. Salah satu faktor yang mempengaruhi baik dan tidaknya kinerja seseorang adalah lingkungan kerja.

Lingkungan kerja adalah dimana kondisi lingkungan dalam variasi-variasi yang relatif sederhana dalam suhu, kebisingan, penerangan, atau mutu udara mendorong efek-efek yang berarti terhadap sikap terhadap kinerja para pegawai. Selain itu rancangan ruang kerja yang memperhatikan jumlah ruang kerja, tata letaknya, dan tingkat kepuasan pribadi yang di berikan, mempengaruhi kinerja dan tingkat kepuasan pegawai. Dalam hal ini penulis mengamati bahwa di lingkungan kerja BBPPMPV Bisnis dan Pariwisata masih belum optimal.

Dari data diatas, menunjukkan bahwa pencapaian kinerja pegawai Balai Besar Pengembangan Penjamin Mutu Pendidikan Vokasi (BBPPMPV) Bisnis dan Pariwisata belum optimal. Hal ini dapat dilihat dari data Tujuan atau Nilai Sasaran Kerja Pegawai (SKP) pada tahun 2018 mencapai $81,88 \%$, tahun 2019 mencapai 82,61\%, dan tahun 2020 mencapai 83,18\%, dimana data tersebut belum mencapai target yang diinginkan yaitu $100 \%$. Dan juga Penilaian Standar atau Orientasi pelayanan pada tahun 2018 hanya mencapai 87,37\%, tahun 2019 mencapai 87,16\%, dan tahun 2020 mencapai $88,10 \%$, dimana data tersebut belum mencapai target yang diinginkan yaitu 100\%. Lalu Penilaian Umpan balik juga dapat dilihat dari kepemimpinan pada pada tahun 2018 mencapai 4,47\%, tahun 2019 mencapai 4,88\%, dan tahun 2020 mencapai $0,45 \%$, dimana data tersebut belum mencapai target yang diinginkan yaitu $100 \%$. Begitupun dengan Alat dan saran dapat dilihat dari disiplin pada pada tahun 2018 mencapai 86,47\%, tahun 2019 mencapai $86,64 \%$, dan tahun 2020 mencapai $87,59 \%$, dimana data tersebut belum mencapai target yang diinginkan yaitu 100\%. Kemudian Penilaian Kompetensi juga dapat dilihat dari Integritas pada pada tahun 2018 mencapai 91,29\%, tahun 2019 mencapai 91,10\%, dan tahun 2020 mencapai $92,06 \%$, dimana data tersebut belum mencapai target yang diinginkan yaitu $100 \%$. Lalu Penilaian motif dapat dilihat dari Kerja sama pada pada tahun 2018 mencapai 85,94\%, tahun 2019 mencapai $86,02 \%$, dan tahun 2020 mencapai 87,07\%, dimana data tersebut belum mencapai target yang diinginkan yaitu 100\%. Dan Peluang juga dapat dilihat dari Komitmen pada pada tahun 2018 mencapai 86,67\%, tahun 2019 mencapai 86,71\%, dan tahun 2020 mencapai 87,62\%, dimana data tersebut belum mencapai target yang diinginkan yaitu $100 \%$.

Berdasarkan keadaan diatas maka penulis melakukan penelitian yang berjudul "Pengaruh Lingkungan Kerja dan Disiplin Kerja Terhadap Kinerja Pegawai Balai Besar Pengembangan Penjamin Mutu Pendidikan Vokasi (BBPPMPV) Bisnis dan Pariwisata".

\section{TINJAUAN PUSTAKA}

\section{Lingkungan Kerja}

Menurut Sedarmayanti dalam Desi (2015:25) lingkungan kerja adalah keseluruhan alat perkakas dan bahan yang dihadapi, lingkungan sekitarnya dimana seseorang bekerja, metode kerjanya, serta pengaturan kerjanya baik sebagai perseorangan maupun sebagai kelompok. Dalam penelitin ini indikator yang digunakan meliputi: hubungan Karyawan, tingkat kebisingan lingkungan kerja, peraturan kerja, penerangan, sirkulasi udara, keamanan kerja.

\section{Disiplin Kerja}

Menurut Terry dalam Sutrisno (2019:87) menyatakan bahwa "Disiplin adalah alat penggerak karyawan agar setiap pekerjaan berjalan dengan lancar, maka harus diusahakan agar ada disiplin yang baik." Adapun indikator yang digunakan meliputi: taat terhadap aturan waktu, Taat terhadap peraturan perusahaan, taat terhadap aturan perilaku dalam pekerjaan, taat terhadap peraturan lainnya diperusahaan

\section{Kinerja}

$\begin{array}{ccc}\text { Menurut } & \text { Hasibuan } & (2017: 34) \\ \text { mengemukakan } & \text { bahwa } & \text { "Kinerja }\end{array}$


(prestasi kerja) adalah suatu hasil kerja yang dicapai seseorang dalam melaksanakan tugas-tugas yang dibebankan kepadanya yang di dasarkan atas kecakapan, pengalaman, dan kesungguhan serta waktu". Beberapa indikator dari kinerja itu sendiri, yaitu: tujuan, standar, umpan balik, alat atau sarana, kompetensi, motif dan peluang.

\section{METODE}

Penelitian yang dilakukan merupakan penelitian kuantitatif dengan pendekatan deskriptif yaitu metode yang digunakan untuk meneliti pada populasi dan sampel tertentu. Teknik sampling yang digunakan adalah random sampling menggunakan dengan sampel sebanyak 67 responden. pengumpulan data menggunakan instrument penelitian, analisis data bersifat kuantitatif/statistik, dengan tujuan untuk menguji hipotesis yang telah ditetapkan (Sugiyono,2014:29). Sifat penelitian yang digunakan dalam penelitian ini adalah dengan analisis kuantitatif yang bertujuan mengetahui hubungan antara tiga variabel, dimana pendekatan ini memberikan suatu gambaran permasalahan untuk mencari hubungan antara variabel $X_{1}$ (Lingkungan Kerja) dengan variabel $X_{2}$ (Disiplin Kerja) dan variabel Y (Kinerja Pegawai).

\section{HASIL DAN PEMBAHASAN}

Setelah diketahui hasil temuan dalam hal ini kemudian di analisis seberapa baik data tersebut mempresentasikan hasil penelitian yang diangkat, terutama kemapuan dalam menjelaskan seberapa baik Lingkungan Kerja dan Disiplin Kerja terhadap Kinerja Pegawai. Selanjutnya akan dilakukan pembahasan hasil-hasil dalam penelitian ini sebagai berikut :

1. Pengaruh variabel Lingkungan Kerja $\left(X_{1}\right)$

Terhadap Kinerja Pegawai $(Y)$

Berdasarkan analisis hasil perhitungan SPSS versi 20, akan hasil uji t Variabel penelitian Lingkungan Kerja sebagai variabel independen terhadap Kinerja Pegawai sebagai variabel dependen menunjukan hasil nilai $t_{\text {hitung }}$ sebesar 3,713 sedangkan $t_{\text {tabel }}$ dengan tingkat signifikan $10 \%(0,10)$ dan derajat kebebasan $(\mathrm{dk})=\mathrm{n}-\mathrm{k}-1=67-2-1=64$ adalah sebesar 1,669. Dengan melakukan perbandingan yaitu $t_{\text {hitug }} 3,713>1,669$ maka Ho ditolak dan $\mathrm{Ha}$ diterima dengan nilai signifikan sebesar $0,000<$ 0,10 yang artinya koefisien variabel lingkungan berpengaruh positif dan signifikan.

Hasil penelitian ini konsisten dengan penelitian Winda Andriani, Rami Widyanti dan Husnurropiq (2020) "Pengaruh Lingkungan Kerja dan Disiplin Kerja Terhadap Kinerja Karyawan (Study Pada Karyawan Rumah Sakit Islam Banjarmasin)". Dimana dalam penelitiannya menghasilkan bahwa secara parsial variabel lingkungan kerja (X1) berpengaruh dan signifikan terhadap variabel kinerja pegawai (Y) dengan koefisien sebesar 3,747 dengan nilai sig sebesar $0,000<0,05$.

2. Pengaruh Variabel Disiplin Kerja $\left(X_{2}\right)$

Terhadap Kinerja Pegawai (Y)

Berdasarkan analisis hasil perhitungan SPSS versi 20, akan hasil uji t Variabel penelitian Disiplin Kerja sebagai variabel independen terhadap Kinerja Pegawai sebagai variabel dependen menunjukan hasil nilai $t_{\text {hitung }}$ sebesar 5,305 sedangkan $t_{\text {tabel }}$ dengan tingkat signifikan $10 \%(0,10)$ dan derajat kebebasan $(\mathrm{dk})=\mathrm{n}-\mathrm{k}-1=67-2-1=64$ adalah sebesar 1,669. Dengan melakukan perbandingan yaitu $t_{\text {hitug }} 5,305>1,669$ maka Ho ditolak dan $\mathrm{Ha}$ diterima dengan nilai signifikan sebesar $0,000<$ 0,10 yang artinya koefisien variabel disiplin berpengaruh positif dan signifikan.

Hasil penelitian ini konsisten dengan penelitian Winda Andriani, Rami Widyanti dan Husnurropiq (2020) "Pengaruh Lingkungan Kerja dan Disiplin Kerja Terhadap Kinerja Karyawan (Study Pada Karyawan Rumah Sakit Islam Banjarmasin)". Dimana dalam penelitiannya menghasilkan bahwa secara parsial 
variabel disiplin kerja $(X 2)$ berpengaruh dan signifikan terhadap variabel kinerja pegawai ( $\mathrm{Y}$ ) dengan koefisien sebesar 4,011 dengan nilai sig sebesar 0,000 < 0,05 .

3. Pengaruh Variabel Ligkungan Kerja $\left(X_{1}\right)$ dan Disiplin Kerja $\left(X_{2}\right)$ Terhadap Kinerja Pegawai (Y)

Berdasarkan dari hasil pengujian pengaruh simultan variabel bebas terhadap variabel terikatnya diperoleh nilai $\mathrm{F}_{\text {hitung }}=70,959>$ nilai $\mathrm{F}_{\text {tabel }}=2,39$, sehingga $\mathrm{H}_{0}$ ditolak dan $\mathrm{H}_{\mathrm{a}}$ diterima. Sehingga dapat disimpulkan bahwa terdapat pengaruh yang signifikan antara lingkungan kerja dan disiplin kerja terhadap kinerja pegawai BBPPMPV Bisnis dan Pariwisata.

Hasil penelitian ini konsisten dengan penelitian Winda Andriani, Rami Widyanti dan Husnurropiq (2020) "Pengaruh Lingkungan Kerja dan Disiplin Kerja Terhadap Kinerja Karyawan (Study Pada Karyawan Rumah Sakit Islam Banjarmasin)". Dimana dalam penelitiannya menghasilkan bahwa secara simultan variabel lingkungan kerja (X1) dan variabel disiplin kerja (X2) berpengaruh secara bersama-sama terhadap variabel kinerja pegawai $(\mathrm{Y})$ dengan nilai $35.406>$ 3155 maka denga hasil tersebut $\mathrm{H}_{\mathrm{o}}$ ditolak dan $\mathrm{H}_{1}$ diterima.

\section{KESIMPULAN}

Berdasarkan uraian pada bab-bab sebelumnya, dan dari hasil analisis serta pembahasan mengenai pengaruh lingkungan kerja dan disiplin kerja terhadap kinerja pegawai, sebagai berikut:

1. Lingkungan kerja (X1) berpengaruh signifikan terhadap Kinerja Pegawai (Y) ditunjukkan dengan nilai sebesar 3,713 berarti $t_{\text {hitung }}$ lebih besar dari $t_{\text {tabel }}$ sebesar $(3,713>1,669)$ dengan tingkat signifikan sebesar 0,000. Nilai signifikan lebih kecil dari $0,10(0,000<0,10)$, maka dapat disimpulkan bahwa $\mathrm{H}_{1}$ diterima. Sehingga dapat dikatakan bahwa Lingkungan kerja berpengaruh positif secara signifikan terhadap kinerja pegawai. Dari persamaan regresi $\mathrm{Y}=$ $12.467+0.802$ (X1) diketahui nilai konstanta sebesar (12.467) apabila lingkungan kerja itu sama dengan nol, maka kinerja akan bernilai sama besar (12.467). Setelah itu koefisien lingkungan kerja sebesar 0.802 artinya bahwa setiap penambahan satu satuan Lingkungan kerja, maka kinerja akan mengalami kenaikan sebesar 0.802. Lingkungan kerja pada BBPPMPV Bisnis dan Pariwisata mendapatkan respon baik dimana dari 12 pertanyaan dengan 67 respomden mendapatkan rata - rata skor 4,15 termasuk dalam rentang skala 3,404,19 dengan kriteria Baik. Hal ini dapat dilihat dari jawaban responden pada butir pernyataan pada indicator Penerangan yaitu Penerangan ditempat bekerja membantu menyelesaikan pekerjaan yang mendapatkan skor interval 4,26 kategori Sangat Baik

2. Disiplin kerja (X2) berpengaruh signifikan terhadap Kinerja Pegawai $(Y)$ ditunjukkan dengan nilai sebesar 5,305 berarti $t_{\text {hitung }}$ lebih besar dari $t_{\text {tabel }}$ sebesar $(5,305>1,669)$ dengan tingkat signifikan sebesar 0,000. Nilai signifikan lebih kecil dari $0,10(0,000<0,10)$, maka dapat disimpulkan bahwa $\mathrm{H}_{1}$ diterima. Sehingga dapat dikatakan bahwa Disiplin kerja berpengaruh positif secara signifikan terhadap kinerja pegawai. Dari persamaan regresi $Y=17.217+1.094$ (X2) diketahui nilai konstanta sebesar (17.217) apabila disiplin kerja itu sama dengan nol, maka kinerja akan bernilai sama besar (17.217). Setelah itu koefisien lingkungan kerja sebesar 1.094 artinya bahwa setiap penambahan satu satuan Disiplin kerja, maka kinerja akan mengalami kenaikan sebesar 1.094. Lingkungan kerja pada BBPPMPV Bisnis 
dan Pariwisata mendapatkan respon baik dimana dari 8 pertanyaan dengan 67 responden mendapatkan rata - rata skor 3,94 termasuk dalam rentang skala 3,404,19 dengan kriteria Baik. Hal ini dapat dilihat dari jawaban responden pada butir pernyataan pada indikator Taat Terhadap Aturan waktu yaitu Selalu datang tepat waktu yang mendapatkan skor interval 4,17 kategori Baik

3. Lingkungan Kerja $\left(X_{1}\right)$ dan Disiplin Kerja $\left(X_{2}\right)$ berpengaruh terhadap variabel Kinerja Pegawai (Y) sebesar 68,9\%, dilihat dari nilai R-Square (Koefisien determinasi) yang didapat sebesar 0,689. Artinya Lingkungan Kerja $\left(X_{1}\right)$ dan Disiplin Kerja $\left(\mathrm{X}_{2}\right)$ memengaruhi Kinerja Pegawai (Y) sebesar 68,9\%, dan sisanya $31,1 \%$ dipengaruhi oleh faktor lain. Hasil penelitian pada variabel lingkungan (X1) dan disiplin kerja (X2) secara bersamasama nilai $\mathrm{F}_{\text {hitung }}=70,959>$ nilai $\mathrm{F}_{\text {tabel }}=$ 2,39, sehingga $\mathrm{H}_{0}$ ditolak dan $\mathrm{H}_{\mathrm{a}}$ diterima. Sehingga dapat disimpulkan bahwa lingkungan kerja (X1) dan disiplin kerja (X2) berpengaruh secara simultan terhadap kinerja pegawai $(\mathrm{Y})$

\section{Saran}

1. Lingkungan kerja pernyataan yang paling lemah adalah pada pernyataan “Tingkat kebisingan yang ada di lingkungan tempat saya bekerja tidak mempengaruhi kinerja saya dan bisa tetap fokus" indikator tingkat kebisingan linkungan, dengan score rata-rata 3,83 kategori Baik tetapi belum maksimal seperti masih ada beberapa para pegawai yang masih suka mendengarkan musik didalam ruangan sehingga dapat menggangu konsentrasi pegawai lain. Untuk itu saran penulis bagi para pegawai agar tidak melakukan kebisingan didalam ruangan tempat pegawai bekerja.

2. Disiplin kerja pernyataan yang paling lemah adalah pada penyataan "Saya memanfatkan jam istirahat kantor dengan maksimal dan tidak menambah jam istirahat" indikator taat terhadap peraturan lainya diperusahaan, dengan score rata-rata 3,74 kategori Baik tetapi belum maksimal seperti masih ada beberapa para prgawai yang tidak memanfatkan jam istirahat kantor dan suka menambah jam istirahat artinya manfaatkanlah waktu dengan baik, untuk itu saran penulis manfaatkanlah waktu jam istirahat kator dengan lebih baik dan tidak menambah jam istirahat saat waktu yang diberikan.

3. Kinerja pegawai pernyataan yang paling lemah adalah pada penyataan "Perusahaan memberikan kesempatan bagi pegawai untuk memberikan masukan atau ide" indikator peluang, dengan score rata-rata 3,62 kategori Baik tetapi belum maksimal artinya tidak semua para pegawai berpendapat selalu diterima oleh perusahaan, hanya para pegawai tertentu yang memberikan saran atau ide diterima oleh perusahaan tetapi tidak dengan pegawai biasa. Untuk itu saran dari penulis agar kinerja maksimal sebaiknya perusahaan selalu memberikan kesempatan bagi semua pegawai tanpa memandang jabatan, karena dengen begitu semua para pegawai akan lebih bersemagat dalam bekerja utuk mencapai kierja yang maksimal.

4. Bagi penelitian selanjutnya, Penelitian ini memberikan informasi bahwa adanya pengaruh antara Lingkungan Kerja dan Disiplin Kerja terhadap Kinerja pegawai pada BBPPMPV Bisnis dan Pariwisata. Terdapat banyak faktor yang 
berhubungan dengan pencapaian kinerja pegawai yang optimal selain lingkunga kerja dan disiplin kerja. Oleh karena itu, disarankan bagi peneliti selanjutnya untuk melakukan penelitian lebih lanjut tentang faktor-faktor lain yang mempengaruhi kinerja pegawai selain ligkungan dan disiplin.

\section{DAFTAR PUSTAKA}

Afandi, P. (2018). Manajemen Sumber Daya Manusia (Teori, Konsep dan Indikator). Riau: Zanafa Publishing.

Alex S. Nitisemito. (2012) Manajemen Personalia: Manajemen Sumber Daya Manusia, Ed. 3, Ghalia Indonesia,:

Andi Supangat, (2015) Statistika dalam Kajian Deskriftif, Inferensi dan Non Parametic, Edisi Pertama, Jakarta: Kencana Prenada Media Group.

Andriani Winda, Widyanti Rahmi. (2020). Pegaruh Lingkungan Kerja Dan Disiplin Kerja Terhadap Kinerja Karyawan (Study pada Karyawan Rumah Sakit Islam Banjarmasin), Jurnal Komunikasi Bisnis dan Manajemen Vol.7 No. 2.

Armansyah Adi, Azis Idris, Putu Evvy Rossanty Niluh. 2018. Pengaruh Kompensasi dan Disiplin Kerja Terhadap Kinerja Pegawai Kantor BPJS Kesehatan Cabang Palu, Jurnal Ilmu Manajemen Universitas Tadulako, Vol.4 No.3.

Astra Gracia Bunga. (2019). Pengaruh Motivasi Dan Lingkungan Kerja TerhadapKinerja Karyawan Pada PT Triview Geospatial Mandiri Jakarta Selatan. Jurnal Ilmiah Manajemen Forkamma. Vol.2.No.2.

Darmadi. (2020). Pengatuh Lingkungan Kerja Dan Disiplin Kerja Terhadap Kinerja Karyawan Pada Indomart Cabang Kelapa Dua Gading Serpong Kabupaten Tangerang. Jurnal Ilmiah Manajemen Forkamma. Vol.3.No.3.

Ghozali, Imam dan Ratmono, Dwi. (2017). Analisis Multivariat dan Ekonometrika dengan Eviews 10, Badan
Penerbit Universitas Diponegoro: Semarang.

Handoko, T. Hani. (2011). Manajemen Personalia dan Sumberdaya Manusia. Yogyakarta: Penerbit BPFE.

Hasibuan, M.S.P. (2012). Manajemen Sumber Daya Manusia. Edisi Revisi. Cetakan Kesepuluh. Jakarta: PT. Bhumi Aksara.

Hasibuan, M.S.P. (2013). Manajemen Sumber Daya Manusia. Cetakan Ketujuh, Belas, PT.Bumi Aksara, Jakarta.

Hasibuan, M.S.P. (2017). Manajemen Sumber Daya Manusia, Jakarta: PT Bumi Aksara.

Hermawati, R., et al (2020). The Effect of Trilogy Leadership Style and Organization Culture on School Performance: Evidence form Indonesian Senior High School. PalArch's Journal of Archaeology of Egypt/Egyptology, 17(6), 8512-8537.Fdisiplin

Jonnest Runtunuwu Hiskia, Lapian Joyce, Dotulong Lucky. (2015). Pengaruh Disiplin, Penempatan Dan Lingkungan Kerja Terhadap Kinerja Pegawai Pada Badan Pelayanan Perizinan Terpadu Kota Manado, Jurnal EMBA. Vol.3. No.3.

Kasmir, (2016). Manajemen Sumber Daya Manusia (Teori dan Teknik). Jakarta: PT Raja Grafindo Persada.

Kaswan, (2012). Manajemen Sumber Daya Manusia untuk Keunggulan Bersaing Organisasi, Graha Ilmu, Jakarta

Khairani, Sofyan Diana. (2013). Pengaruh Ligkungan Kerja Terhadap Kinerja Kerja Pegawai BAPPEDA, Jurnal MIEJ, Vol.2. No.1

Kusniawati Aini, Nurhayati, Herlina Rosy. (2014). Pegaruh Lingkungan Kerja Dan Disiplin Kerja Terhadap Kinerja Karyawan Pada PT Garpuraning Rahayu Ciamis, Jurnal Ekonologi Vol.1 No.1.

Maisarah, Hasibuan Siti, Bahri Syaful. (2018). Pengaruh Kepemimpian, Lingkugan Kerja dan Motivasi Kerja Terhadap Kinerja, jural Ilmiah Magister Manajemen, Vol.1. No.1. 
Mangkunegara, A.A Anwar Prabu. (2011). Manajemen Sumber Daya Manusia. Bandung: PT. Remaja Rosdakarya

Mangkunegara, A.A Anwar Prabu. (2015). Sumber Daya Manusia Perusahaan, Cetakan Kedua belas, Bandung: PT. Remaja Rosdakarya

Mangkunegara, A.A Anwar Prabu. (2017). Manajamen Sumber Daya Manusia Perusahaan, Bandung: Karya Abadi.

Nawawi, Hadari. (2011). Manajemen Sumber Daya Manusia Untuk Bisnis Yang Kompetitif. Yogyakarta: Gadjah Mada University Press.

Nurjaya, N., et al. (2021). Pengaruh Etos Kerja Dan Disiplin Kerja Terhadap Kinerja Pegawai Pada Dinas Kehutanan Dan Perkebunan Kota Bogor. JENIUS (Jurnal Ilmiah Manajemen Sumber Daya Manusia), 4(2), 172-184.

Sagita, Novyanti Joyce. (2019). Pegaruh Motivasi Kerja, Lingkungan Kerja Dan Disiplin Kerja Terhadap Kinerja Pegawai Pada BAPPEDA Provinsi Sulawesi Tengah, Jurnal Katalogis Vol.3 No.1.

Santoso, Singgih. (2015). Menguasai Statistik Multivariat. Jakarta : PT Elex Media Komputindo.

Sedarmayanti, (2011). Manajemen Sumber Daya Manusia, Reformasi Birokrasi Dan Manajemen Pegawai Negeri Sipil, Cetakan Kelima, Bandung: PT Refika Aditama.

Sedarmayanti. (2015). Manajemen Sumber Daya Manusia, Bandung: Refika Aditama

Sugiyono, (2014). Metode Penelitian Pendidikan Pendekatan Kuantitatif,
Kualitatif, dan RED. Bandung: Alfabeta.

Sugiyono, (2016). Metode Penelitian Pendidikan Pendekatan Kuantitatif, Kualitatif, dan RED. Bandung: Alfabeta.

Sugiyono, (2017). Metode Penelitian Pendidikan Pendekatan Kuantitatif, Kualitatif, dan RED. Bandung: Alfabeta, CV.

Sunarsi, D., et al. (2021, January). The Influence of Motivation and Work Discipline on Employee Performance at the Yogyakarta Tourism Service. In Proceeding The First International Conference on Government Education Management and Tourism (Vol. 1, No. 1, pp. 1-7).

Sunyoto, Danang. (2015). Penelitian Sumber Daya Manusia. Yogyakarta: CAPS (Center Of Academic Publishing Service).

Sutrisno, Edy (2011). Manajemen Sumber Daya Manusi, Jakarta: Kencana.

Sutrisno, Edy. (2019). Manajemen Sumber Daya Manusia. Jakarta: Prenadamedia Group.

Terry, George R. (2013). Principles of Management. Homewoodlllnois, Record D. Irwin, 7rd Edition.

Veithzal Rivai. (2014). Proses Arti Pelatihan ,Jakarta.

Wibowo, (2016). Manajemen Kinerja, Cetak Kelima, PT.Rajagrafindo Persada Jakarta-14240.

Wilandari, D. F., et al. (2021). Pengaruh Penilaian Kerja Terhadap Kinerja Karyawan Pada PT. Jaya Mandiri Rekabuana di Cilandak. Jurnal Ekonomi Efektif, 3(2). 